\title{
O FÓRUM SOCIAL MUNDIAL COMO UM ESPAÇO EDUCADOR
}

\author{
SÉrgio HADDAD ${ }^{1}$
}

\begin{abstract}
RESUMO: O objetivo do artigo é analisar o Fórum Social Mundial, nascido no contexto dos grandes movimentos antiglobalização do final do século XX, como espaço educador. Este texto descreve a história do fórum, desde o lançamento, em Porto Alegre, no ano de 2001, até os dias de hoje, analisando-o na ótica dos estudos sobre os movimentos sociais. $\mathrm{O}$ foco analítico sobre os desafios dos processos educativos que se dão em seu contexto é fundamentado na concepção de educação popular. Este artigo debate os desafios políticos e metodológicos enfrentados ao longo desses quase 20 anos de existência do Fórum Social Mundial, apontando para questões futuras, numa conjuntura em rápida mudança. Trata-se de um ensaio construído a partir de revisão bibliográfica sobre documentos e a literatura pertinente.
\end{abstract}

Palavras-chave: Fórum Social Mundial. Movimentos sociais. Educação popular. Antiglobalização. Sociedade civil.

\section{WORLD SOCIAL FORUM AS AN EDUCATING SPACE}

\begin{abstract}
The purpose of the article is to analyze the World Social Forum, born in the context of the great anti-globalization movements of the late $20^{\text {th }}$ century, as an educating space. This text describes the forum's history, from its foundation, in Porto Alegre, in the year 2001, to date, analyzing it from the perspective of social movement studies. The analytical focus on the challenges of educational processes that take place in its own context is based on the conception of popular education. This paper discusses the political and methodological challenges the forum has faced over these almost 20 years of existence, and points to future issues in a fast-changing conjuncture. This text is an essay built from literature review on documents and relevant literature.
\end{abstract}

Keywords: World Social Forum. Social movements. Popular education. Anti-globalization. Civil society. 


\section{EL FORO SOCIAL MUNDIAL COMO UN ESPACIO EDUCATIVO}

RESUMEN: El propósito del artículo es analizar el Foro Social Mundial, nacido en el contexto de los grandes movimientos antiglobalización de finales del siglo $\mathrm{XX}$, como un espacio educativo. Este texto describe la historia del foro, desde su lanzamiento, en Porto Alegre, en el año de 2001, hasta los días de hoy, analizándolo desde la perspectiva de los estudios sobre movimientos sociales. El enfoque analítico sobre los desafíos de los procesos educativos que tienen lugar en su contexto se basa en la concepción de la educación popular. Este artículo analiza los desafíos políticos y metodológicos enfrentados durante estos casi 20 años de existencia del Foro Social Mundial, señalando problemas futuros, en una coyuntura que cambia rápidamente. Este es un ensayo construido a partir de una revisión bibliográfica sobre los documentos y la literatura pertinente.

Palabras-clave: Foro Social Mundial. Movimientos sociales. Educación popular. Antiglobalización. Sociedad civil.

\section{Introdução}

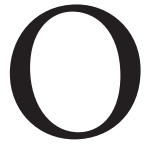

avanço do neoliberalismo no mundo, no fim do século XX - estimulado pelos governos Thatcher, no Reino Unido, e Regan, nos Estados Unidos, e pela queda do muro de Berlim -, provocou inúmeras reações de organizações da sociedade civil, entidades sindicais e movimentos sociais em países do norte, com amplas mobilizações iniciadas em Seattle (Estados Unidos), principalmente contra as entidades multilaterais criadas pelo sistema Bretton Woods (Banco Mundial e Fundo Monetário Internacional) e a Organização Mundial do Comércio. De modo crescente, cidades como Washington (Estados Unidos), Québec (Canadá), Praga (República Tcheca), Londres (Inglaterra), Davos (Suíça) e Gênova (Itália), em sequência, sediaram novos protestos, chamados antiglobalização.

Como desdobramento, e em diálogo com tais movimentos, em Porto Alegre, no Brasil, nasceu o Fórum Social Mundial (FSM), em 2001, com a intenção de não apenas confrontar o neoliberalismo, mas também trocar e propor alternativas ao modelo econômico vigente, que vinha produzindo graves consequências sociais. Esse fórum reuniu em um mesmo espaço lideranças e ativistas nacionais e internacionais. Discutia-se outro modelo de globalização, baseado na justiça social e na democracia participativa.

Este ensaio tem como foco analisar as diversas dimensões educativas do FSM sob a ótica dos estudos sobre educação popular. Em sua primeira parte, o texto descreve a história desses encontros até os dias atuais, com foco analítico nos estudos sobre movimentos sociais. Na sequência, discute o FSM como um espaço educador. Finalmente, conclui com algumas questões que desafiam a conjuntura atual e os desdobramentos para a luta contra o neoliberalismo.

\section{Histórico}

Em fevereiro do ano 2000, representantes de organizações e movimentos sociais brasileiros ${ }^{1}$ se reuniram em São Paulo para discutir a proposta de realizar um Fórum Social Mundial como contraponto ao Fórum Econômico Mundial, que, desde 1971, realizava encontros em Davos, na Suíça. Essa cidade se tornou um polo no qual líderes políticos, grandes empresários e representantes de organismos internacionais 
promoviam negócios e divulgavam uma lógica única de aprofundamento do capitalismo globalizado de vertente neoliberal.

O grupo acolheu a sugestão do editor do jornal Le Monde Diplomatique de Paris, Bernard Cassen, de realizar o evento em Porto Alegre, cidade que se tornara conhecida internacionalmente por sua experiência de orçamento participativo ${ }^{2}$. Argumentou que seria um local exemplar para criar um contraponto a Davos: enquanto os grupos de interesses mais agudos do capital produziam um mundo de desigualdades e reuniam-se em local sofisticado na Suíça, aqueles que defendiam e lutavam por justiça social, direitos humanos e mais democracia se encontrariam, na mesma data, em um país entre os mais desiguais do mundo, mas que vivia, naquele momento, um processo de democratização, com experiências inovadoras de governos progressistas pós-ditadura militar.

Com a queda do muro de Berlim, em 1989, e o avanço do capitalismo frente ao socialismo, a promessa de Davos era ampliar o mercado de consumo, incluindo países do sul com governos de orientação liberal e implantação do livre comércio de crescente produção de mercadorias. A globalização era impulsionada pela revolução dos meios de comunicação e da informática, o que facilitava a circulação de informações e de bens. Reagan, nos Estados Unidos (1981-1989), e Thatcher, na Inglaterra (1979-1990), apresentaram-se, desde os anos 1980, como principais impulsionadores das políticas neoliberais para essa nova fase do capitalismo: a diminuição do papel do Estado, a privatização de seus bens, a abertura do mercado e a desregulamentação e redução dos gastos sociais, sob orientação, principalmente, do Fundo Monetário Internacional (FMI), do Banco Mundial e da Organização Mundial de Comércio (OMC).

Diante das políticas desta nova fase do capitalismo e suas consequências sociais, setores da população se organizaram como uma frente de resistência e confronto. Em 30 de novembro de 1999, 50 mil manifestantes bloquearam as ruas de Seattle, nos Estados Unidos, por ocasião da reunião da OMC, para protestar contra suas políticas, provocando a suspensão do encontro. As mobilizações se espalharam quando das reuniões do FMI, do Banco Mundial, das cúpulas da União Europeia, do G-8, da Organização para a Cooperação e Desenvolvimento Econômico (OCDE), da OMC e do Fórum Econômico Mundial, em várias partes do mundo. Chamados, inicialmente, de altermundialistas (ou movimento antiglobalização) ${ }^{3}$, esses protestos tiveram como auge a reunião do G-8, na cidade de Gênova, em julho de 2001, quando cerca de 300 mil pessoas ocuparam as ruas, mesmo com forte repressão do governo Berlusconi, que resultou na morte do manifestante Carlo Giuliane . $^{4}$

O FSM nasceu na esteira dessas manifestações. Sem relegar espaço aos protestos, colocou maior acento nas denúncias e, principalmente, nas propostas. Nas palavras de um dos seus primeiros organizadores:

Tornara-se necessário intensificar a denúncia da perversidade dessa lógica quanto à justiça social, à superação da desigualdade e o respeito às diversidades, além de mostrar que havia outros caminhos para a humanidade e gente por toda parte experimentando e lutando por alternativas. Era preciso, por outro lado, fazer renascer a esperança, que definhava (WHITAKER et al., 2019, p. 20).

Para contemplar o desejo de buscar alternativas e renovação da esperança, a mensagem que marcou o FSM foi: "Um outro mundo é possível" (LEITE, 2003, p. 12). A proposta do fórum foi apresentada pelo coletivo de brasileiros, em junho de 2000, para cerca de 500 representantes de movimentos sociais e organizações internacionais de resistência à globalização neoliberal, reunidos em Genebra para protestar contra a Cúpula Social da ONU Copenhagen + 5. Ao mesmo tempo, encontros com representantes dos governos do estado do Rio Grande do Sul e da Prefeitura de Porto Alegre foram realizados para pedir apoio, esclarecendo o caráter não partidário do fórum e sua ênfase na sociedade civil ${ }^{5}$. 
Em janeiro de 2001, para surpresa dos organizadores, aproximadamente 20 mil pessoas ocuparam o espaço do FSM, representando uma diversidade de movimentos, organizações não governamentais, representantes de pastorais ${ }^{6}$, grupos de mulheres, ativistas dos movimentos negro e LGBT, juventudes e profissionais de universidades. Como delegados ${ }^{7}$ oficiais, havia 2.500 nacionais e 1.500 internacionais, de 117 países. A cobertura jornalística foi feita por veículos de comunicação de 52 países.

Para garantir a dimensão internacional da reflexão produzida pelo fórum, o grupo organizador convidou ativistas e intelectuais de vários países para participar com convidados nacionais em 16 painéis de 4 participantes cada, estruturados pelos seguintes eixos temáticos: produção de riquezas e reprodução social; acesso às riquezas e sustentabilidade; afirmação da sociedade civil e dos espaços públicos; poder político e ética na nova sociedade. Os painéis funcionaram ao lado de várias outras atividades propostas, organizadas e realizadas pelos delegados na perspectiva da autogestão.

Dado o caráter inovador e inclusivo da sua organização, o FSM ganhou relevância em um curto espaço de tempo, dando continuidade às características dos movimentos anteriores: uma iniciativa da sociedade civil, independentemente de governos e partidos, constituída como rede, sem representantes ou porta-vozes. A autogestão de atividades permitiu a abertura para as diversidades de grupos e propostas. Conforme Leite, outro dos organizadores iniciais:

[o FSM] estabelece uma nova forma de fazer política, um espaço que tem como referência a ideia de rede, estruturada horizontalmente, e não a pirâmide hierárquica, de modo a reduzir os pontos de disputa e potencializar a dinâmica do encontro, diálogo e colaboração. O Fórum Social Mundial é um espaço aberto, e não uma organização e uma instituição, em que a quase totalidade das atividades são auto-organizadas pelos participantes, os partidos políticos são deslocados do centro da cena para a condição de coadjuvantes e nenhuma assembleia ou resolução pretende falar pelo conjunto dos presentes. A diversidade é aí respeitada e valorizada como uma força, e não uma debilidade do movimento: se "um outro mundo é possível”, será um “mundo onde caibam muitos mundos” (LEITE, 2003, p. 12).

Essa nova forma de atuar da sociedade civil, com força nas dimensões socioculturais e de modo horizontal, ganhou relevância e reflexão entre estudiosos dos movimentos sociais e das ações coletivas. Alonso (2009), ao analisar as diversas teorias de movimentos sociais a partir dos anos 1960, aborda três famílias: a Teoria de Mobilização de Recursos (TMR), a Teoria dos Processos Políticos (TPP) e a Teoria dos Novos Movimentos Sociais (TNMS). A primeira afirma que a decisão de agir dos indivíduos é motivada por cálculo racional, em lógica de custo e benefício, e só constituiria ação coletiva na medida em que houvesse disponibilidade de recursos materiais, apoiadores e coordenação desses indivíduos. Já TPP e TNMS enveredam por um caminho em que o elemento cultural ganhou importância explicativa, tendo por base analítica as mudanças geradas no capitalismo em meados do século XX, que amenizaram os conflitos de caráter trabalhista, não só pelas conquistas realizadas no âmbito da relação capital-trabalho, mas também pela ampliação do papel do Estado na oferta de direitos. Dessa maneira, TPP e TNMS:

nasceram dos debates sobre a revolução, ou melhor, da exaustão dos debates marxistas sobre a possibilidade de revolução. Ambas se insurgiram contra explicações deterministas e economicistas da ação coletiva e contra a ideia de um sujeito histórico universal. As duas constroem explicações macro históricas que repelem a economia como chave explicativa e combinam políticas e cultura na explicação dos movimentos sociais (ALONSO, 2009, p. 54). 
Ao colocar foco na dominação cultural como fator de conflitos, as mobilizações coletivas poderiam ser explicadas para além das classes sociais e dos conflitos trabalhistas; ampliando para oposições encontradas entre grupos excluídos, como negros, indígenas, mulheres, homossexuais, jovens, idosos e outros que fogem ao padrão da "normalidade" sociocultural vigente. Analisando a família da TNMS, Alonso nomina Alan Touraine, Jürgen Habermas e Alberto Melucci, e encontra confluência em suas análises sobre os movimentos sociais nos anos recentes:

para todos, uma mudança macrossocial teria gerado uma nova forma de dominação, eminentemente cultural (por meio da tecnologia e da ciência) e borrado as distinções entre o público e o privado, acarretando mudanças nas subjetividades e uma nova zona de conflito. As reivindicações teriam se deslocado dos itens redistributivos, do mundo do trabalho, para a vida cotidiana, demandando a democratização de suas estruturas e afirmando novas identidades e valores. Estaria em curso uma politização da vida privada. Os movimentos de classe dariam lugar, assim, a novos movimentos expressivos, simbólicos, identitários, caso do feminismo, do pacifismo, do ambientalismo, do movimento estudantil. Isto é, os movimentos mais em evidência no momento em que escreviam (ALONSO, 2009, p. 67).

As estratégias utilizadas por esses novos movimentos sociais no seu embate em torno do reconhecimento das suas identidades e demandas têm por base uma organização de outra natureza, mais fluida, não hierárquica, descentralizada, desburocratizada e voltada à sociedade civil (mais do que ao Estado e ao mercado). No entanto, a partir das críticas feitas sobre os limites interpretativos das três famílias analisadas, Alonso chega a uma convergência mínima:

em torno da tese de que os movimentos sociais não surgem pela simples presença de desigualdade, nem resultam diretamente de cálculos de interesses ou valores. As mobilizações envolvem tanto ações estratégicas, cruciais para o controle sobre bens e recursos que sustentam a ação coletiva, quanto formação de solidariedades e identidades coletivas (ALONSO, 2009, p. 72).

Gohn (2011), ao traçar um histórico dos movimentos sociais na América Latina, localiza no início do século XXI o retorno do ativismo social em ações coletivas, com o ressurgimento de movimentos étnicos que resultaram em governos populares, como Bolívia e Equador, considerados plurinacionais, ou de natureza nacionalista, como a Venezuela. A autora também encontra ressurgimento de movimentos urbanos, atores sociais até então à sombra, como os piqueteiros, na Argentina, cocaleiros, em Bolívia e Peru, e zapatistas, no México. Prevê ainda, a constituição de redes internacionais, como a Via Campesina, e alianças entre movimentos rurais e urbanos, bem como movimentos sindicais em diversas formas de luta social. Finalmente, Gohn destaca os movimentos transnacionais, como os movimentos alter- ou antiglobalização.

Essa natureza dos movimentos sociais contemporâneos, em suas características de atuação com mecanismos de empoderamento e construção de conhecimento em defesa dos seus direitos, encontra-se no FSM desde os primeiros anos. Realizado o primeiro evento em Porto Alegre, o sucesso pôde ser medido pelo entusiasmo revelado no título da edição de janeiro de 2001 do Le Monde Diplomatique: "O século XXI começa em Porto Alegre." As inserções na mídia e, principalmente o contraponto produzido com o fato de ter sido organizado no mesmo período de Davos, estimulou os organizadores a continuarem com o FSM. 
Foi elaborada uma carta de princípios baseada na experiência do primeiro encontro, de modo a orientar os planos futuros, além de ser constituído o Conselho Internacional (CI), estabelecido em 2001, integrado por representantes de redes temáticas, movimentos e organizações internacionais e regionais. $\mathrm{O}$ CI passou a ser uma instância política e operacional, que funcionava por comissões ${ }^{8}$, contribuindo tanto na definição dos rumos estratégicos do FSM quanto na sua mobilização, na sua internacionalização e no estímulo à organização de fóruns temáticos e regionais ${ }^{9}$.

Nos anos seguintes, o FSM ganharia dimensão e interesse internacionais. O segundo fórum, realizado em Porto Alegre, entre os dias 31 de janeiro e 05 de fevereiro de 2002, superou todas as previsões em número de participantes, com mais de 50.000 pessoas. Com os mesmos eixos temáticos, foram realizados 96 seminários, 27 conferências e 622 atividades autogestionadas. A terceira edição, também em Porto Alegre, de 23 a 28 de janeiro de 2003, continuou em número crescente de participantes e atividades. Cem mil pessoas estiveram presentes, sendo que 25 mil instalados no acampamento da juventude ${ }^{10}$.

Por decisão do Conselho Internacional, o FSM percorreria o mundo, visando sua internacionalização. O local escolhido para o $4^{\circ}$ FSM foi Mumbai, na Índia (de 16 a 21 de janeiro de 2004). Membros do Conselho Internacional visitaram o país e estimularam a criação de um comitê organizador indiano, que se encarregou da organização. O FSM 2004 inovou, com a presença massiva da casta mais desfavorecida da sociedade indiana, os dalits, tornando-se mais inclusivo de setores populares. Diferentemente do que ocorria em Porto Alegre, com performances de artistas famosos ao fim de cada dia, as atividades culturais foram intercaladas às demais atividades, em caráter de educação popular, com mais de 1.500 artistas, poetas, dramaturgos, escritores e cineastas exibindo seus trabalhos. Foram apresentadas 150 peças de teatro de rua e um festival de filmes com mais de 85 títulos sobre os principais temas do FSM. Cresceu também o número de voluntários que ajudaram a organizar o fórum, com destaque especial para 180 intérpretes e tradutores voluntários de Argentina, Brasil, Índia, Estados Unidos, França, Espanha, Reino Unido, Bélgica, Suíça, Sri Lanka, Tailândia, Indonésia, Japão, Coreia e Palestina.

A cada FSM, novas aprendizagens ocorreram. Em 2005, novamente em Porto Alegre (de 26 a 31 de janeiro), a construção da programação seguiu uma nova metodologia, ampliando as convergências e procurando evitar a repetição desarticulada de atividades sobre o mesmo tema. O primeiro passo foi realizar uma consulta temática por meio de questionário amplamente divulgado, o qual procurava identificar lutas, questões, problemas, propostas e desafios que as diversas organizações participantes consideravam relevantes à discussão, assim como a definição de quais atividades tais organizações pretendiam realizar em Porto Alegre. As respostas analisadas pelas comissões de Metodologia e Conteúdo do Conselho Internacional resultaram em onze espaços temáticos de cinco eixos transversais, que guiaram todas as atividades.

A edição de 2006 ocorreu de maneira descentralizada, com três cidades sediadas em três diferentes continentes: Bamako, Mali (de 19 a 23 de janeiro); Caracas, Venezuela, e Karachi, Paquistão (de 24 a 29 de março) - cada evento com suas metodologia e programação próprias, construídas a partir de consulta aos participantes. Dois desses eventos não se organizaram no mesmo período do fórum de Davos.

Em 2007, o FSM mundial ocorreu em Nairóbi, Quênia (de 20 a 25 de janeiro). Foram definidos nove temas gerais a partir de uma ampla consulta, que ocorreu entre junho e agosto de 2006. Uma novidade metodológica desse fórum foi a criação de um quarto dia de atividades, voltado para apresentação e socialização das propostas de ações produzidas nos dias anteriores. Essa inovação ocorreu como primeira resposta a críticas sobre a invisibilidade das propostas produzidas no fórum.

A partir de Nairóbi, os fóruns passaram a ser realizados a cada dois anos. Assim, o FSM de 2009 voltou ao Brasil, em Belém, Pará. O encontro foi marcado pela presença dos presidentes latino-americanos Evo Morales, Rafael Correa, Hugo Chávez, Fernando Lugo e Lula da Silva, líderes de governos progressistas 
convidados pelos organizadores. Também foi marcante a presença de povos indígenas, principalmente da Amazônia (SADER, 2013).

Dois anos depois (de 6 a 11 de fevereiro de 2011), ocorreu outro fórum no continente africano, em Dacar, Senegal. Doze países africanos presentes elaboraram ampla reflexão sobre as questões do continente, com destaque para a presença magrebina naquele momento inicial de insurgência cidadã nos países árabes. Dessa maneira, produziu-se a conexão de questões locais em nível internacional com os processos de mudanças reais que se articulavam no mundo (GRZYBOWSKI, 2011).

Na mesma lógica, em 2013, o FSM aconteceu em Túnis, Tunísia (de 26 a 30 de março) - pela primeira vez no mundo árabe. A escolha do local deveu-se ao fato de ser aquele o país que iniciou a Primavera Árabe. Em 2015, ainda impactado pelas mobilizações populares, o FSM voltou a Túnis, reunindo cerca de 45.000 ativistas de 4.400 organizações e movimentos provenientes de 120 países. A delegação brasileira contou com mais de 200 pessoas, representando cerca de 100 organizações e movimentos.

O próximo país escolhido foi o Canadá, na cidade de Montreal, de 9 a 14 de agosto de 2016, distanciando-se do período de realização do Fórum Econômico de Davos. Apesar das dificuldades de obtenção de visto por parte de muitos ativistas, o FSM ocorreu com mais de 35 mil participantes advindos de 125 países. Essa foi a primeira edição realizada no hemisfério norte.

Finalmente, de 13 a 17 de março de 2018, o FSM voltou ao Brasil, em Salvador, com fortes tendências de diálogo entre Brasil, toda América Latina e o continente africano, aproveitando o fato de ser sediado no estado com maior concentração de população negra do país.

Além dos FSM, diversos fóruns menores, nacionais, regionais, locais ou temáticos ocorreram em várias partes do mundo. Entre a edição de Belém, em janeiro de 2009, e o fim de 2010, registraram-se 55 fóruns que adotaram a Carta de Princípios e aplicaram a auto-organização de atividades. A cultura do FSM incentivou esses eventos, que se organizaram autonomamente. Ao longo da sua existência, o FSM conviveu com outras formas de mobilizações de repercussão internacional e características semelhantes, apesar de possuírem objetivos e resultados diferentes, como a Primavera Árabe, os Indignados (Espanha), o Occupy (Estados Unidos), a Revolução das Panelas (Islândia), os Piqueteiros (Argentina) e as Jornadas de Junho (Brasil). Esses movimentos reproduziam a horizontalidade na ocupação de espaços públicos abertos à participação diversa da sociedade e na forte utilização dos meios digitais para sua organização. Comunicação e mobilização operavam em rede, com baixa institucionalidade e representação partidária, com plataformas constituídas pelo diálogo e a participação.

Podem tais ações coletivas ser consideradas movimentos sociais nos moldes tradicionalmente conceituados? Não caberia aqui uma resposta, pela natureza deste artigo, mas o que se pode constatar é que, nas sociedades contemporâneas, expressões de diversidade social vêm ganhando espaço e sua presença na cena pública aponta novas questões diante dos tradicionais movimentos sociais. Segundo Sherer-Warren,

[n] as sociedades globalizadas, multiculturais e complexas, as identidades tendem a ser cada vez mais plurais e as lutas pela cidadania incluem, frequentemente, múltiplas dimensões do self: de gênero, étnica, de classe, regional, mas também dimensões de afinidades ou de opções políticas e de valores pela igualdade, pela liberdade, pela paz, pelo ecologicamente correto, pela sustentabilidade social e ambiental, pelo respeito à diversidade e às diferenças culturais etc. As redes, por serem multiformes, aproximam atores sociais diversificados - dos níveis locais aos mais globais, de diferentes tipos de organizações -, possibilitam o diálogo da diversidade de interesses e valores (SHERER-WARREN, 2006, p. 115).

O FSM é um desses espaços de expressão da diversidade produzida pela sociedade. 


\section{O FSM como um Espaço Educador}

Ao analisar o FSM como espaço de aprendizagem, muitos são os aspectos que poderíamos considerar. Desde o princípio, sua organização foi pensada a partir dos conceitos da educação popular.

O caráter educativo do FSM, ligado às raízes da tradição da educação popular, foi revisitado em um processo de luta amplo e global. Definida como prática social a serviço de grupos populares, a educação popular, além da sua intencionalidade política, lida com conteúdo e método. Os conteúdos são afeitos às análises e às estratégias das lutas sociais que, no caso do FSM, incorporaram, em grande medida, a dimensão internacional. As metodologias têm se preocupado com as modalidades ativas e participativas, em que a ação do grupo se propõe horizontal e democrática, sem reproduzir formas de dominação e individualismo (BRANDÃO, 1984).

O FSM toma como método a produção de aprendizagens coletivas por meio do diálogo. Isso pode ser verificado tanto nas atividades autogestionadas quanto nas ações realizadas nas ruas e no acampamento da juventude, por exemplo, nas quais jovens de diversos países, sentados em roda, debatem ideias, produzem atividades culturais e trocam informações, aprendendo coletivamente.

Em meio aos escombros de um mundo decadente, encontramos um espaço para sonhar, criar, dançar, pensar, aprender a lição necessária de globalizar a resistência e a esperança. Encontramos em Porto Alegre uma cidade livre, onde gerações, gêneros, etnias, religiões e nacionalidades formaram um mosaico humano democrático, expressando sonhos coletivos, respeitando todas as diferenças e construindo alternativas (SILVEIRA, 2002, p. 112).

A metodologia do FSM, ao buscar facilitar as convergências entre os(as) participantes, carrega em si uma dimensão educativa. Sob a frase afirmativa e ampla "um outro mundo é possível" (LEITE, 2003, p. 12), os participantes, ao se reunirem em diversidades temáticas e organizativas, veem-se desafiados a construir consensos políticos. O slogan afirmativo contribuiu para ampliar a base dos frequentadores, mas seria ingenuidade entendê-lo como ausência de conflitos de interesses. Nesse sentido, o modelo de organização, os métodos e o conjunto de valores e princípios comuns do fórum procuraram orientar para a negociação política voltada a construir convergências, sem descaracterizar as diferenças naturais dos atores sociais. A realização do encontro procurou romper com a tradição de se reunir apenas entre pares, como sindicalistas, camponeses e ONG, estimulando-os ao diálogo amplo.

Vale a pena tomar alguns pontos da Carta de Princípios do FSM (CARTA..., 2001), em que são reafirmadas suas natureza e orientações básicas. Nela, o fórum foi definido como "um espaço aberto de encontro, plural e diversificado, não confessional, não governamental e não partidário" que "não se constitui em instância de poder, a ser disputado pelos participantes de seus encontros". Diz-se que "ninguém estará autorizado a exprimir, em nome do Fórum [...] posições que pretenderiam ser de todas/os as/os seus/suas participantes", bem como que "@s participantes não devem ser chamad@s a tomar decisões, por voto ou aclamação, enquanto conjunto de participantes do Fórum”. Por outro lado, está "assegurada, a entidades ou conjuntos de entidades que participem dos encontros do Fórum, a liberdade de deliberar [...] sobre declarações e ações que decidam desenvolver", que o Fórum difunde amplamente. O FSM é um espaço aberto ao "pluralismo e à diversidade de engajamentos e atuações", "conviverá com contradições e será sempre marcado pelo conflito de opiniões entre as entidades e movimentos que se colocam nos marcos de sua Carta de Princípios". O FSM "não opera com base em convites. Ele viabiliza condições para que todos que queiram promover suas atividades, sob qualquer nome (oficinas, seminários, encontros, fóruns etc.), possam fazê-lo. Nenhuma entidade ou organização cujo perfil esteja em concordância com os princípios do FSM teve ou terá negada a sua participação nos seus eventos. ” 
Essa forma aberta de organização do FSM marcou sua natureza participativa e plural, sem deslegitimar nem impedir os esforços por consensos sistematizados; a novidade estaria na forma de produzi-los. As grandes conferências, os testemunhos, as atividades de diálogo e controvérsia, normalmente realizados por convite dos organizadores de cada fórum ou do CI, são eventos em que se espelhariam os acúmulos das reflexões e das estratégias de lutas, produzidos por intelectuais e lideranças sociais. Já as atividades autogestionadas, de maneira complementar, recolheriam o cotidiano das lutas individuais e coletivas, suas análises e impressões a partir da inserção local, regional, nacional ou internacional. A convergência entre elas poderia permitir o avanço das lutas sociais, num processo permanente de diálogo para construção de novas reflexões e estratégias, uma das dimensões da educação popular.

Pleyers (2010), baseado em pesquisas realizadas nos sete primeiros fóruns e no acompanhamento de outros encontros, em México, França e Bélgica, analisou a relação entre ativistas globais do movimento alterglobalização e ativistas locais e nacionais. Segundo o pesquisador, aqueles que operam em redes internacionais, concentrando sua atuação na esfera global, acabam por viajar de um país a outro, de reunião em reunião, perdendo contato com os "ativistas de base" (PLEYERS, 2010). Para o autor, as lideranças internacionais tiveram um protagonismo nas orientações dos primeiros fóruns sociais, participando do Conselho Internacional, ajudando na elaboração da Carta de Princípios, definindo temas e palestrantes a compor mesas de debate e colocando em xeque a ideia de globalização horizontalizada, por relegar aos ativistas de base uma posição secundária. Para o autor, houve negligência às dinâmicas das raízes locais, ao considerarem-nas instrumentos para conseguir apoio político para os principais desafios situados no plano global. Por outro lado, ativistas locais passaram a questionar a efetividade das agendas dos fóruns internacionais no plano local. Isso se tornou um grande desafio a ser enfrentado pelos movimentos que operam tanto no plano global quanto no local.

No entanto, segundo o autor, o ambiente coletivo de aprendizagem facilitou o encontro e o diálogo entre essas duas concepções: algumas das principais ideias dos ativistas de orientação local foram adotadas nos espaços globais e vice-versa, prevenindo localismos ou atores globais desconectados e possibilitando uma criativa e produtiva interação de conteúdos e estratégias locais e internacionais.

Ao revisar 1.286 oficinas do III FSM, realizado em Porto Alegre no ano de 2003, Streck identificou temáticas vinculadas ao campo das práticas da educação popular presentes naquele momento histórico: educação e gestão democrática, pois as conquistas da democracia e da cidadania são também processos pedagógicos; educação e arte, tema com grande número de oficinas que trabalham a dimensão estética, sugerindo "que dificilmente haverá um outro mundo na ausência de poesia, do belo" (STRECK, 2004, p. 62) ${ }^{11}$; educação, sustentabilidade e trabalho, temas ligados ao mundo do trabalho, à falta de empregos e sua precarização, assim como à questão ambiental; educação, multiculturalismo e globalização, a cultura como expressão de classe, como espaço simbólico em constante reconfiguração; cultura e os meios de comunicação; e educação e gênero.

Ao identificarmos as ênfases temáticas ao longo do tempo, podemos perceber que elas repercutem os momentos conjunturais e os locais em que os encontros foram realizados. No entanto, algumas temáticas têm se mostrado mais permanentes, como é o caso das lutas das mulheres. Uma das redes feministas globais ativas no FSM desde os primeiros anos é a Marcha Mundial das Mulheres. A rede colocou como desafio fortalecer a agenda de gênero no movimento antiglobalização, reconhecendo nele um importante espaço para construir novas análises, aprendizagens e formas de organização. 
No processo preparatório à participação nos primeiros anos do FSM, a marcha desencadeou um conjunto de trabalhos educativos que resultou em aprendizagens, trabalhos esses que acabaram por se concretizar no evento. Como relatam duas dirigentes da marcha:

[n]a passeata de abertura do FSM em 2003 nós da Marcha conseguimos expressar o processo de preparação que desencadeamos. Os estandartes de abertura foram concebidos e costurados em oficinas onde refletimos sobre nossas vidas, nossas visões para o futuro e o significado do Fórum para isso. A batucada trazia um longo trabalho de reutilização de latas e mulheres aprendendo a dar o ritmo e o tom. A composição da ala era uma aliança construída com a juventude presente no Acampamento e com o movimento de lésbicas, gays e travestis. Essa alegria e essa irreverência têm nos mantido firmes e fortes em momentos de embate, como em Quito, Québec e Cancún, e estreitada nossa aliança com setores do feminismo que emergem independentes ou com poucos pontos de contato com o feminismo chamado histórico, como as anarcofeministas, os grupos de ação direta, ou as imigrantes francesas do "Nem putas, nem submissas" (NOBRE; FARIA, 2003, p. 628).

Nobre e Faria (2003, p. 630) apontam também que a diversidade de movimentos e organizações sobre a questão de gênero esteve presente nos debates e na busca por alternativas e propostas comuns. No entanto, reconhecem que nem sempre esse diálogo foi fácil e, por isso, acabaram por construir agendas amplas, muitas vezes até contraditórias Diante das dificuldades de produzir unidades, cada grupo acabou seguindo seu próprio caminho. $\mathrm{O}$ mesmo ocorreu em relação à afirmação da agenda feminista no contexto dos movimentos antiglobalização em função do acúmulo de temáticas e estratégias, além da exigência de viagens internacionais em um contexto de poucos recursos e tempo. Em virtude das dificuldades encontradas, a marcha acabou por colocar ênfase na formação de grupos de jovens que estudam feminismo e têm como perspectiva trabalhar em ONG ou grupos de ativismo, de discussão, fanzines, rádios livres ou outros espaços de atuação. No caso do ativismo internacional, optou-se por circular informação e formar ativistas locais que pudessem participar dos eventos internacionais sem precisar viajar de um canto a outro para atender a agenda global.

Outra questão, no campo da educação popular, que foi motivo de reflexão entre parcelas dos participantes do FSM diz respeito ao tipo de conhecimento produzido pelos movimentos sociais e organizações, bem como à validade desse conhecimento para a construção de um pensamento não hegemônico. Mesmo reconhecendo que muitas práticas horizontais bebem do conhecimento científico e tecnológico hegemônico das sociedades, Santos afirma que:

as práticas e saberes que circulam no FSM têm a sua origem em pressupostos epistemológicos (o que conta como conhecimento) e em pressupostos ontológicos (o que conta como humano) muito distintos. Essa diversidade existe não só entre os diferentes movimentos, mas também dentro de cada um deles (SANTOS, 2005, p. 138).

No entanto, a ação de policiamento e repressão por parte dos saberes hegemônicos não permite a viabilização dos saberes não hegemônicos, que acabam convertidos em matéria-prima (como o caso do conhecimento indígena e camponês sobre a biodiversidade) ou são rejeitados à luz de critérios falsos de verdade e de eficácia. O grande desafio, portanto, seria a construção de um conhecimento baseado em epistemologias alternativas às hegemônicas, que produzissem conhecimentos vinculados às práticas das lutas sociais de setores populares. Uma dessas iniciativas nascidas no FSM foi a Universidade Popular 
dos Movimentos Sociais (UPMS). Partindo da constatação de que grande parte do mundo acadêmico e de pesquisadores opera de maneira apartada das práticas dos movimentos sociais e, por outro lado, que movimentos e instituições que atuam na base da sociedade não têm um corpo teórico que lhes permita refletir criticamente sobre sua prática, a iniciativa das UPMS se organizou na perspectiva de:

contribuir para preencher esse hiato e corrigir as duas deficiências que ele produz. Em última análise, o seu objetivo é ultrapassar a distinção entre teorias e práticas, conjugando-as através de encontros sistemáticos entre os que se dedicam essencialmente à prática de transformação social e os que se dedicam essencialmente à produção teórica (SANTOS, 2005, p. 138).

Baseada em uma perspectiva freiriana, vivenciada na perspectiva da educação popular, a UPMS se propõe:

superar a distinção convencional entre ensinar e aprender - baseada na distinção entre professor e aluno -, criando assim contextos e momentos de aprendizagem recíproca. $\mathrm{O}$ seu ponto de partida é o reconhecimento da ignorância recíproca. O seu ponto de chegada é a produção compartilhada de saberes tão globais e diversos como os próprios processos de globalização (SANTOS, 2005, p. 138).

O FSM mostra-se, portanto, como espaço facilitador da diversidade de práticas educativas, voltadas tanto ao intercâmbio de experiências e informações quanto ao seu caráter de formação de novas gerações para o debate e a participação dirigido para a ação social.

\section{Considerações Finais}

O FSM, ao longo dos anos, depois de um período de grande crescimento, perdeu visibilidade nas mídias e nas agendas do altermundialismo. Nascido no ápice do movimento alterglobalização, como espaço de encontro de grupos, movimentos sociais e indivíduos, o FSM tanto produziu críticas ao neoliberalismo quanto realizou propostas alternativas ao modelo de organização da sociedade no final do século XX e início do XXI.

Mesmo perdendo visibilidade, o FSM continuou sendo realizado em muitas partes do mundo, sem que se tenha a verdadeira dimensão do seu impacto, dada a multiplicidade de atividades ocorridas em seu nome. Ao analisarmos sua trajetória, vale ressaltar que três temas indissociáveis sempre estiveram sobre a mesa desde 2001: os objetivos políticos, a metodologia para atingi-los e o impacto dos conhecimentos produzidos e disseminados no seu espaço, sejam eles análises de realidades, sejam estratégias de luta, sejam construção de projetos de sociedade.

Para Gadotti, o FSM é um espaço que serve para educar para outro mundo, porque visibiliza o que foi escondido para oprimir, além de abrir espaço aos que não são escutados. Esse autor reconhece ainda que o fórum atende à necessidade de ter uma educação para a era da globalização, para uma consciência planetária, não para a consciência de Estados-nação, modelados pelo pensamento da modernidade (GADOTTI, 2007, p. 190). Participar do processo do FSM, das suas atividades, e tomar conhecimento de pessoas de outras nacionalidades, com outras culturas e experiências, ajudariam na constituição da consciência de que um outro mundo possível só será construído graças a essa dimensão global, afirma Gadotti (2007, p. 190). 
As orientações produzidas pela experiência da educação popular na América Latina ajudaram a dar forma à sua metodologia que, influenciada pelo pensamento de Paulo Freire, esteve presente nos diversos encontros ao redor do mundo ocorridos em nome do FSM. Nesses espaços, a possibilidade de diálogo com experiências de outros continentes permitiu um profícuo intercâmbio de ideias e práticas.

A forma como o FSM foi construído e sua metodologia, expressa em sua Carta de Princípios, deram sustentação à posição daqueles(as) que viram no espaço do fórum um local de troca, aprendizagens e construção de múltiplas agendas. No entanto, sistematizar a riqueza do conhecimento trazida e produzida nesse contexto permanece sendo um grande desafio, dada as suas dimensão e diversidade.

O enfraquecimento da presença pública do fórum e da visibilidade nas mídias têm múltiplas explicações. Uma delas é o próprio enfraquecimento dos movimentos sociais na conjuntura global atual. Há também analistas que explicam por fatores internos e de governança, questionando suas proclamadas horizontalidade e independência de partidos políticos.

À medida que o êxito do FSM se incrementa, aumentam também as críticas recebidas. Entre as mais habituais estão: a escassa democracia do encontro; a ênfase nas conferências de importantes intelectuais versus o ativismo horizontal e o trabalho de base; a presença majoritária da classe média europeia e latino-americana; a presença crescente de partidos e líderes políticos (como Chávez ou Lula); a burocratização e a institucionalização, entre outros elementos. Algumas dessas tensões acentuam as diferenças entre os ramos da proposta e do protesto, minando a credibilidade do FSM entre muitos movimentos sociais de base (BRINGEL; MUÑOZ, 2010, p. 34).

Não cabe a este artigo desenvolver todas as implicações políticas do modo de ser do FSM e de sua existência, tampouco as críticas que, ao longo do tempo, foram sendo realizadas, algumas incorporadas ao longo de sua história, outras não. Vale destacar, no entanto, que o principal embate político se deu entre aqueles que demandam declarações unitárias como sínteses das lutas sociais e aqueles que, ao contrário, defendem a multiplicidade de vozes a se expressarem por suas bandeiras de luta, argumentando que a síntese não seria possível, dada a natureza diversa das lutas sociais e dos atores políticos na sociedade atual, além das dificuldades metodológicas para realizá-las.

Apesar dos inúmeros debates sobre o fórum, seu sentido político e sua organização, ele continua a existir como ideia, congregando um conjunto considerável de pessoas, entidades e movimentos que lutam contra a ordem hegemônica do capitalismo atual. Seus desafios não estão aparentemente nas diversas formas de práticas educativas que ele propicia, mas sim na capacidade de sistematização e multiplicação do que se produz. Em fevereiro de 2018, uma parte do grupo dos brasileiros que iniciou a caminhada do FSM assinou um documento público sobre o seu futuro no qual apontam como uma das grandes dificuldades enfrentadas ao longo do tempo a sistematização e a transmissão dos conhecimentos produzidos nos seus encontros:

O FSM, contudo, não cria lutas ou movimentos; apenas potencializa o que existe, aquilo que é construído na diversidade de resistências às opressões, injustiças e exploração, e de utopias pelo mundo. Ele expressa, e nele se expressam, os problemas das correlações de forças, da construção de ferramentas, da radicalização ou moderação, ou da internacionalização ou nacionalização das lutas, da unidade ou dispersão dos movimentos, da estatização ou autonomia da ação política e dos fluxos e refluxos das conjunturas e períodos. Certamente no FSM foram cometidos erros e mais poderia ter sido feito, por exemplo, na comunicação para fora de suas iniciativas e debates, ou ampliando o aprendizado das experiências, ou 
mesmo a transmissão delas entre gerações e camadas de ativistas. Talvez o mais angustiante seja que, na medida em que o tempo passa, muito da riqueza do aprendizado gigantesco que realizamos deixa de ser retransmitido para novas gerações de ativistas e pode se perder (WHITAKER et al., 2018, p. 6).

Como propiciar o encontro e a interlocução entre as diversas redes e temas de modo a permitir que, não apenas os diretamente interessados se apropriem do produto do seu grupo, mas também que sirva de influência para outros grupos de interesse? Como transformar este espaço criativo e multifacetado de ideias e práticas em mecanismos de influência e diálogo com o poder público e com a sociedade, construindo e contemplando critérios de prioridades não discriminatórios e excludentes? Como tornar o FSM mais inclusivo em relação aos diversos grupos sociais, àqueles pouco organizados ou com dificuldades para participar dos grandes eventos de maneira a ampliar presencialmente as suas vozes? São desafios permanentes do FSM.

\section{Notas}

1. As organizações eram as seguintes: Associação Brasileira de Organizações Não Governamentais (ABONG); Ação pela Tributação das Transações Financeiras em Apoio aos Cidadãos (Attac sp); Comissão Brasileira Justiça e Paz (CBJP) da Conferência Nacional dos Bispos do Brasil (CNBB); Associação Brasileira de Empresários pela Cidadania (CIVES); Central Única dos Trabalhadores (CUT); Instituto Brasileiro de Análises Sociais e Econômicas (IBASE); Movimento dos Trabalhadores Rurais Sem Terra (MST); Rede Social de Justiça e Direitos Humanos.

2. Processo pelo qual governos consultam a população sobre as prioridades na aplicação dos seus recursos orçamentários. O governo de Porto Alegre foi um dos pioneiros na implantação dessa política, a partir de 1989.

3. Sobre as diversas denominações do movimento e suas características, ver Bringel e Muñoz (2010).

4. Uma ótima descrição do histórico dessas manifestações, assim como sobre as influências recebidas por outros movimentos, pode ser encontrada em Leite (2003).

5. Para análises das origens, do desenvolvimento e das dinâmicas do FSM nos seus primeiros anos, ver Leite (2003), Loureiro et al. (2002), Miná (2003), Cassen (2003) e Cattani (2001). Consultar também a biblioteca digital do FSM (http://www.memoriafsm.org).

6. Sobre as pastorais, ver Levy (2009).

7. Inicialmente, o FSM fazia uma distinção entre as inscrições daqueles que representavam organizações e movimentos da sociedade civil (delegados) e as inscrições individuais.

8. Por exemplo, comissão de finanças, conteúdo, expansão, metodologia, comunicação.

9. Inúmeros fóruns regionais e temáticos surgiram como desdobramento do FSM, produzidos por comissões organizadoras próprias, seguindo a carta de princípios.

10. Os acampamentos da juventude passaram a ser frequentes e crescentes em número de jovens, os quais, mesmo participando das atividades gerais, mantinham programação própria, com convidados do fórum e outros, de acordo com os interesses votados em seus coletivos.

11. A Carta Maior, por exemplo, produziu uma importante publicação, compilando a cobertura jornalística da sua agência no FSM de 2003, reveladora dos temas tratados no evento (CARTA MAIOR..., 2004). 


\section{Referências}

ALONSO, A. A teoria dos movimentos sociais: Um balanço do debate. Lua Nova, São Paulo, v.76, p. 49-86, 2009.

BRANDÃO, C. R. Educação popular. São Paulo: Brasiliense, 1984.

BRINGEL, B.; MUÑOZ, E. E. Dez anos de Seattle, o movimento antiglobalização e a ação coletiva transnacional. Ciências Sociais Unisinos, São Leopoldo, v. 46, n. 1, p. 28-36, jan.-abr. 2010.

CARTA DE PRINCÍPIOS DO FÓRUM MUNDIAL SOCIAL. Porto Alegre, 2001. Disponível em: https:// wsf2018.org/carta-de-principios-do-forum-social-mundial/. Acesso em: 13 set. 2019.

CARTA MAIOR. III Fórum Social Mundial. São Paulo: Carta Maior Publicações e Promoções Ltda., 2004.

CASSEN, B. Tout a commencé à Porto Alegre. Paris: Librairie Arthème Fayard, 2003.

CATTANI, A. D. (orgs.). Fórum Social Mundial: A construção de um mundo melhor. Porto Alegre/ Petrópolis: Editora da UFRGS/Vozes, 2001.

GADOTTI, M. Educar para um outro mundo possível. São Paulo: Publisher Brasil, 2007.

GOHN, M. G. Movimentos sociais na contemporaneidade. Revista Brasileira de Educação. Rio de Janeiro, v. 16, n. 47, p. 333-362, mai.-ago. 2011.

GRZYBOWSKI, C. Um balanço do Fórum Social Mundial 2011. Carta Maior. Carta Capital., 2011. Disponível em: https://www.cartacapital.com.br/internacional/um-balanco-do-forum-social-mundial-2011. Acesso em: 13 set. 2019.

LEITE, J. C. Fórum Social Mundial: A história de uma invenção política. São Paulo: Fundação Perseu Abramo, 2003.

LEVY, C. Influencia e contribuição: A Igreja Católica progressista brasileira e o Fórum Social Mundial. Cadernos ISER, Rio de Janeiro, n. 29, v. 2, p. 1-8, 2009.

LOUREIRO, I.; LEITE, J. C.; CEVASCO, M. E. O espírito de Porto Alegre. São Paulo: Paz e Terra, 2002.

NOBRE, M.; FARIA, N. Feminismo em movimento: Temas e processos organizativos da Marcha Mundial das Mulheres no Fórum Social Mundial. Estudos feministas, Florianópolis, v. 11, n. 2, p. 623-632, jul.-dez. 2003.

MINÁ, G. Um outro mundo é possível. São Paulo: Record, 2003.

PLEYERS, G. The Global Justice Movement. Globality Studies, n. 19, p. 1-9, jul, 2010.

SADER, E. Uma breve história do Fórum Social Mundial. Carta Maior, 2013. Disponível em: https://www. cartamaior.com.br/?/Editoria/Movimentos-Sociais/Uma-breve-historia-do-Forum-Social-Mundial/2/14704. Acesso em: 13 set. 2019.

SANTOS, B. S. O Fórum Social Mundial: manual de uso. São Paulo: Cortez Editora, 2005.

SHERER-WARREN, I. Das mobilizações às redes de movimentos sociais. Sociedade e Estado. Brasília, 2006, v. 21, n. 1, p. 109-130, 2006. 
SILVEIRA, L. H. Fórum social mundial: Impressões. Porto Alegre: CORAG, 2002.

STRECK, D. R. O Fórum Social Mundial e a agenda da educação popular. Revista Brasileira de Educação, Rio de Janeiro, n. 26, p. 58-68, mai.-ago. 2004.

WHITAKER, F. O desafio do Fórum Social Mundial: um modo de ver. São Paulo: Fundação Perseu Abramo/ Loyola, 2005.

WHITAKER, F. et al. Fórum Social Mundial: espaço aberto ou organização? Algumas ideias a respeito das discussões sobre o futuro do FSM. 2018. Disponível em: https://entreleslignesentrelesmots.blog/2018/02/20/ forum-social-mondial-espace-ouvert-ou-organisation-quelques-idees-a-propos-des-discussions-sur-lavenirdu-fsm/. Acesso em: 13 set. 2019.

\section{Sobre o Autor}

SÉrgio Haddad é pesquisador da Ação Educativa e professor do PPGEd da Universidade de Caxias do Sul, Possui doutorado em História e Filosofia da Educação.Estuda políticas públicas, movimentos sociais, educação de jovens e adultos e educação popular. É pesquisador sênior do CNPq. Líder de grupo de pesquisa "Juventude e Práticas Educativas em Educação de Jovens e Adultos”.

Recebido: 11 Fev 2020

Aceito: 02 Mar 2020 